This is the final peer-reviewed accepted manuscript of:

Tasquier, G., Levrini, O., \& Dillon, J. (2016). Exploring students' epistemological knowledge of models and modelling in science: results from a teaching/learning experience on climate change. International Journal of Science Education, 38 (4), 539-563.

The final published version is available at: http://dx.doi.org/10.1080/09500693.2016.1148828

Rights / License:

The terms and conditions for the reuse of this version of the manuscript are specified in the publishing policy. For all terms of use and more information see the publisher's website.

This item was downloaded from IRIS Università di Bologna (https://cris.unibo.it/)

When citing, please refer to the published version. 


\title{
Exploring Students' Epistemological Knowledge of Models and Modelling in Science: Results From a Teaching/Learning Experience on Climate Change
}

\author{
Giulia Tasquier $^{\mathrm{a} *}$, Olivia Levrini ${ }^{\mathrm{b}}$, Justin Dillon ${ }^{\mathrm{c}}$ \\ ${ }^{a}$ Department of Physics and Chemistry, University of Palermo, Italy; ${ }^{b}$ Department of Physics and \\ Astronomy, University of Bologna, Italy; ${ }^{c}$ Science \& Technology Education Group, King's College \\ London, London, UK.
}

\begin{abstract}
The scientific community has been debating climate change for over two decades. In the light of certain arguments put forward by the aforesaid community, the EU has recommended a set of innovative reforms to science teaching such as incorporating environmental issues into the scientific curriculum, thereby helping to make schools a place of civic education. However, despite these European recommendations, relatively little emphasis is still given to climate change within science curricula.

Climate change, although potentially engaging for students, is a complex topic that poses conceptual difficulties and emotional barriers, as well as epistemological challenges. Whilst the conceptual and emotional barriers have already been the object of several studies, students' reactions to the epistemological issues raised by climate changes have so far been rarely explored in science education research and thus are the main focus of this paper.

This paper describes a study concerning the implementation of teaching materials designed to focus on the epistemological role of "models and the game of modelling" in science and particularly when dealing with climate change. The materials were implemented in a course of 15 hours (five 3-hour lessons) for a class of Italian secondary school students (grade 11;16-17 years old). The purpose of the study is to investigate students' reactions to the epistemological dimension of the materials, and to explore if and how the material enabled them to develop their epistemological knowledge on models.
\end{abstract}

Keywords: science education; climate change; models and modelling in science; epistemology; secondary-school students.

\section{Introduction}

Despite climate change being one of the five major problems facing humanity in this century (Horizon, 2020), many reports highlight that there is still little emphasis on it within science curricula (Osborne \& Dillon, 2008). The need to renew science curricula is indeed highlighted by many reports and surveys. In fact, the present structure of science curricula, coupled with teaching and assessing issues, seems to work against the goal of fostering a life-long interest in the sciences (Osborne \& Dillon, 2008). Introducing environmental issues into the curriculum might hence have two important implications. It would offer students the opportunity to learn more about socio-scientific topics and contribute to a more sustainable future (Author et al., 2002) as well as helping to engage and support them in learning more about science (Author, 2012; Svihla \& Linn, 2011). Although environmental issues have proved to be engaging for students, addressing climate change at school is challenging from many points of view. It implies addressing conceptual difficulties, overcoming behavioural barriers and developing refined epistemological skills.

Within the field of physics education research, important studies have investigated the conceptual difficulties that students encounter in understanding greenhouse effect and its relationship

\footnotetext{
* Corresponding author: Department of Physics and Astronomy, University of Bologna, Viale Berti Pichat 6/2, 40127, Bologna, Italy. Email: giulia.tasquier2@,unibo.it.
} 
with global warming. More specifically, research has revealed the following issues (Besson, De Ambrosis, \& Mascheretti, 2010; Author, 2013): (i) infrared emission of bodies is usually not taken into account as an energy-loss mechanism, (ii) emittance, when considered, is often confused with reflectance, (iii) students tend to give absolute meaning to properties like transparency, absorptivity and emissivity, rather than seeing them as interactive properties, (iv) radiation is often confused with heat, and (v) students tend to apply a temporal or linear causal reasoning (Rozier \& Viennot, 1991) for explaining processes instead of causal schemes based on balancing and equilibration (diSessa, 2014). These tendencies lead students to interpret the greenhouse effect with the naif metaphor of "trapping" (Besson et al., 2010) which is not only misleading but also ineffective for grasping concepts such as feedback. The known difficulties are not surprising since the crucial physics concepts involved in understanding the greenhouse effect (e.g. transparency) are often treated superficially, both in textbooks and by teachers (Besson et al., 2010). Furthermore, the traditional organization of scientific content in theories could in itself be responsible for creating barriers in understanding the greenhouse effect, considering that this is clearly an intra-disciplinary issue (Author et al., 2014). Having acknowledged the difficulties discussed above, several scholars produced teaching proposals, materials and applets for use in class to improve students' understanding (e.g. Besson et al., 2010; Svihla \& Linn, 2011).

The challenge of producing citizens who feel personally involved in such a social issue is, however, much more complex than simply enabling students to understand the greenhouse mechanism. Researchers in the social sciences have been investigating for years why citizens tend to deny the climate change problem and are still relatively resistant to becoming involved in it (Lorenzoni, Nicholson-Cole, \& Whitmarsh, 2007; Weintrobe, 2012). Examples of barriers proven to hinder personal involvement can be summed up as follows (Author et al., 2014):

a) not individual but collective - climate change is not perceived as an individual problem, but rather as a collective one (Pongiglione, 2012), i.e. several studies in psychology demonstrate that shared responsibility leads to a diminished sense of responsibility from the single individual (Weintrobe, 2012).

b) too big or too small - scarce knowledge of climate change effects also causes individuals to view the hazard as either too trivial and irrelevant for everyday life (Leiserowitz, 2006), or as so major that the individual feels entirely helpless in front of the problem and thus prefers to ignore it in order to avoid feelings of fear, guilt and hopelessness (Weintrobe, 2012).

c) too far - The climate change issue is seen as a distant problem, one which will not affect the current generation and can thus be ignored (Lorenzoni et al., 2007). People are generally unwilling to deal with long-term problems (Oppenheimer \& Todorow, 2006), especially those which require "payment today" in return for hypothetical benefits to future generations.

Whilst conceptual and emotional barriers have already been the subject of several studies, students' reactions to the epistemological issues raised by climate change are little explored explicitly in science education research. The main epistemological issues that can represent a demanding challenge for students and, more generally for citizens, are obviously related to the fact that climate science implies non-linear models whose features are very different from the classic and mechanistic view of modelling (Pasini, 2003). However, puzzling epistemological issues also arise when very basic models are used in an introduction to the greenhouse effect, which could easily leave students sceptical and detached (Author et al., 2014). Difficulties in coping with the models of greenhouse effect are, for example, highlighted by Svihla and Linn (2011) when, in the investigation of the comprehensibility of visualization, they observed students' tendency of reading a software 
visualization literally: "When asked, 'Based on your observations, what happens to energy from the sun (solar radiation) when it reaches the Earth?' students might explain, 'when the arrow hit the ground it turns out to little red dots. Then when they come out they turn to little arrow again, but the arrows are purple and red"" (Svihla \& Linn, 2011). The researchers interpreted the evidence as a problem in the software and addressed this tendency by adding annotated screenshots of the visualization. In our opinion, students' reactions can be instead interpreted as a sign of a deeper problem with the meaning and the role of models in greenhouse simulations: How can a balance mechanism be represented in a simulation? How can emission be modelled so as to emphasise that it is different from reflection and that is it not the result of a transformation of the absorbed energy ${ }^{l}$ ?

In the paper of Niebert and Gropengiesser ${ }^{2}$ (2012), students' difficulties with models can be deduced by the implicit metaphors used for conceptualizing the mechanism of climate change. Students indeed tend to base their reasoning on simplistic metaphors (the metaphor of atmosphere as a container with a lid) built on linear causal reasoning (Viennot, 2014) that fails in capturing the mechanism of balancing and equilibrium. Also Niebert and Gropengiesser (2012), like Svihla and Linn (2011), address students' difficulties by acting on the representations themselves. In this second case, students are progressively guided to revise the metaphors.

In our paper, we present and discuss a teaching experience based on materials that we designed to emphasize the role and the meaning of models and modelling in learning climate science. Those materials were implemented in an extended intervention (15 hours) in a class of secondary school students (16-17 years old) and the aim of the study presented here is to investigate whether and how students' developed their epistemological knowledge of models and modelling whilst they learnt about climate science. In order to reach such a research aim, during the implementation, many different data were collected and original analytic tools designed.

Although the paper is empirically-oriented, it still aims to achieve goals that reach beyond the specific area, climate change, to which the empirical study refers: i) to provide a contribution to the methodological problem of designing analytic tools in order to investigate if and how students' epistemological discourse on models and modelling evolve in real classes and ii) to provide new arguments for enriching the debate in science education about the role of modelling in learning.

\section{Theoretical Framework and Research Question}

Although modelling is considered a fundamental part of any authentic scientific inquiry (Giere, 2004; Godfrey-Smith, 2006; Nersessian, 2002), much work is needed in order to turn models and modelling into an essential feature of school science teaching. Authoritative EU and US reports (e.g. Millar \& Osborne, 1998; National Research Council 1996; Rocard, Csermely, Jorde, Lenzen, WalwergHeriksson, \& Hemmo, 2007) ascribe two crucial roles to modelling in teaching: i) since models are at the heart of scientific inquiry, they are fundamental for developing epistemological knowledge about the nature of science; ii) the development of epistemological competencies on modelling are needed in a complex risk society. Numerous research studies in science education advocate and support the relevance of model-based science education (Nersessian, 2002). Two main strands oriented our work: (1) theoretical and/or empirical studies where types, features and functions of models are discussed with regard to their educational relevance, and/or where models and modelling are investigated as teaching/learning tools for developing students' or teachers' specific knowledge, competencies and skills; (2) empirical studies that investigate students' difficulties in dealing with 
modelling and/or studies that apply specific investigation tools and strategies for fostering and evaluating the development of students' epistemological knowledge.

Within the first strand, many studies describe the benefits of engaging students in a modelbased science education: (i) it provides students with opportunities to become acquainted and feel more comfortable with scientific practices (e.g. Hestenes, 1992); (ii) it fosters students' conceptual development (e.g. White, 1993), (iii) it enhances the understanding of abstract concepts through the exploration of concrete, visual structures (Barab, Hay, Barnett, \& Keating, 2000) and (iv) it fosters the meta-cognitive abilities necessary to improve learning, such as the ability to express and externalize thinking (Gilbert J.K., 1995; White, 1993). Other research studies stress the potential of modelling in developing epistemic skills (e.g. Carey \& Smith, 1993; Pluta, Chinn, \& Duncan, 2011) and fostering productive epistemologies of science (Gilbert S.W., 1991; Schwarz \& White, 2005). Further studies highlight the benefits of modelling for developing fundamental life skills, such as awareness of the semantic relation between theory and phenomena (Gilbert J.K., 2004; Greca \& Moreira, 2000), metaphorical competencies which underlie every language (Lakoff \& Johnson, 1980) and analogical causal reasoning (diSessa, 2014; Harrison \& Treagust, 2000). Additionally, many model-centred tools and educational software (e.g. StarLOGO, STELLA, and ThinkerTools) have been implemented in order to promote subject matter expertise, inquiry skills, and systems thinking (Schwarz \& White, 2005). An interesting study that oriented our analysis concerns the philosophical underpinnings of how models are addressed in physics education (Koponen, 2007). In this study, Koponen concluded that "The model-based view of science education strives for authenticity in science teaching, and many of its advocates seek support from philosophical perspectives related to realistic versions of the Semantic View of Theories". Koponen argues that such philosophical underpinnings are too strong to produce an authentic picture of physics practice where a more pragmatic attitude toward models is adopted. In particular, he retains that an authentic image of physics requires only minimum realism and he suggests that physics education should focus on concepts like reliability, accuracy and usefulness of model instead of trying to demonstrate models' truth.

The second research strand includes empirical studies aimed at investigating students' and/or teachers' epistemological positions on models. Some of these studies show the lack of explicit and aware epistemological stances (e.g. VanDriel \& Verloop, 1999) or the resistance of views consistent with a naïve realist epistemology. As highlighted by Grosslight et al, "[students] are more likely to think of models as physical copies of reality that embody different spatio-temporal perspectives than as constructed representations that may embody different theoretical perspectives" (Grosslight, Unger, Jay, \& Smith, 1991). The roots of such miscomprehension have been related to the limited emphasis and span given in teaching to the roles, purposes and functions of models in science (Treagust, Chittleborough, \& Mamiala, 2002). Without enough span or a refined epistemological guide, students are left with hyper-simplified and stereotyped views of models where the expression constructed representation is perceived as synonymous of not real and too subjective to be scientific. In the paper of Author et al (2015a), an articulated reaction of a class of students to the representation function of models and theories is described. As regards the representation issue, students were torn between the perception of being faced with something very puzzling and the concern that it could undermine the roots of one's own image of physics, based on categories like certainty, objectiveness and truth.

The empirical studies led to the production of a rich variety of investigative tools, from Likerttype questionnaires to clinical interviews, involving also open-ended questionnaires. These 
investigative tools differ in their proximity/distance to specific contexts in the questions, as well as in the quantitative or qualitative analysis they imply. In some cases, students or teachers are asked to recognize modelling processes in specific physics problems concerning, for example, thermal phenomena or electric circuits (e.g. Etkina, Warren, \& Gentile, 2005; Fazio, Battaglia, \& Di Paola, 2013). In other cases, students are asked to answer general epistemological questions on model types, functions, definitions or application (e.g. VanDriel \& Verloop, 1999).

Rather than addressing unsolved problems in science education research, the analysis presented in this paper aims to enrich the research on models and modelling by showing and discussing opportunities that climate change physics can offer to increase the span of roles, purposes and functions of models in science. This contribution will emerge from the discussion of the results achieved to answer the following specific research question:

RQ. How did students' epistemological knowledge on modelling evolve during the implementation of a teaching experience on climate change? How such an evolution can be revealed?

\section{Research Context and Methods}

The teaching experience consisted of an after-school laboratory-course held in a science oriented Italian secondary school (Author, 2015b). The course involved one class of 28 students (grade 11; 16 year olds) and was structured in five lessons as shown in the table below (table 1).

Table 1. Structure and content of the lab-course

$1^{\text {st }}$ Introduction to climate change: the scientific research and new terms of the scientific controversy The aim of lesson 1 is to stress what is shared by the scientific community (e.g. the increase of temperature of the Earth surface; the reduction of the ice-surface and the ice-thickness) and what is still object of controversial issues. In particular, by referring to the IPCC reports, it is stressed that: i) warming of the climate system is unequivocal, ii) global warming is very likely [90\%] due to anthropogenic causes of greenhouse gases increases, and iii) the origin of many controversies is the intrinsic difficulty in producing mathematical and physical models able to take into account a huge number of variables.

During this lesson, students are introduced to climate science and progressively guided to grasp: i) how climate science is located within science and what are its specificities with respect to meteorology; ii) what are the data and the main evidence that lead scientists to argue that we are in front of significant climate changes; iii) what characterises climate systems and the climate models and why they are "complex". The crucial point of the lesson from a conceptual dimension is the introduction of the notion of feedback, presented as a typical way of reasoning in complex systems and, hence, in climatology.

$2^{\text {nd }}$ Experiments on examples of interaction between radiation and matter

The interaction between matter and radiation is here investigated through a guided-inquiry aimed at leading the students through the development of simple experiments in which some objects are heated in the process of being exposed to a radiation source. In these experiments the objects are aluminium cylinders with different colours and the sources are bulbs with different spectrum.

In this lesson there are several conceptual points that students were asked to face explicitly:

- what characterizes thermodynamics behaviour or optic behaviour (e.g. to differentiate between heat and radiation);

- the concept of equilibrium (e.g. why an object exposed to sun reaches an equilibrium temperature and from what kind of properties the equilibrium temperature - or stationary temperature - is dependent); 
- the concepts of absorbance $(a)$, reflectance $(r)$ and transmittance $(t)$, as well as the Stefan-Boltzmann law and Kirchhoff's law.

In dealing with the previous concepts, it is emphasized that: $a-r-t$ are properties which describe the interaction between matter and radiation; all bodies emit according to their temperature; in a stationary condition there is a balance between the incoming and the out-coming energy. Fundamental steps of this phase are to construct the phenomenological relation between absorbance of a body and its temperature and to stress absorbance as the crucial property for interpreting the thermal effects of radiation.

$3^{\text {rd }}$ Experiments for the construction of a Greenhouse model

The aim of lesson 3 is to guide students to construct a model of a "greenhouse", which can explain why and how a change in atmospheric composition can produce temperature rise on the Earth's surface. A very simple model is chosen based on a set of essential hypotheses, including: the Earth is modelled as a black body; the atmosphere is modelled as a uniform and homogeneous layer (metaphorically imaged like a sheet of plastic); radiation is assumed constant and average only on two wavelengths, in particular short waves for incoming and long waves for the outgoing; and the absorbance of the atmosphere is assumed to have only two values, according to the two wavelengths. In spite of these simplifications the model is argued to be suitable to enable students to get acquainted with reasoning in terms of energy balance and to understand the formal relation between atmosphere absorbance and earth surface temperature.

The power of this model is that it strongly and directly stresses that if the absorbance of the atmosphere (for long wave radiation) increases, then the Earth's surface and atmospheric temperature increases in order to keep the balance with the incoming radiation. This relation between absorbance and temperature has several implications. One is that absorbance can be interpreted as the bridge between anthropogenic causes (i.e. greenhouse gasses emissions) and the physical explanation of GW. Another implication of that relation is the opportunity it gives to exemplify, by means of physical phenomena, like the melting ices, the concept of feedback mechanism: the melting ice causes an increase of water vapour, carbon dioxide and methane gas (that are some of the major greenhouse gasses), so their emission in the atmosphere causes an increase of absorbance that in turn causes an increase of temperature (example of circular causality, so that causes and effects cannot be clearly distinguished).

$4^{\text {th }}$ The epistemological perspective of complexity: Introduction to the basic concepts for looking at complex systems

The aim of lesson 4 is to introduce some concepts typical of the perspective of complexity so as to refine the epistemological discourse. In particular the notion of feedback is re-analysed to stress the epistemological distinction between linear and circular causality, previously introduced, where circular causality means that: i) causes and effects cannot be clearly distinguished; ii) small changes, in space and time, can produce big changes. Moreover, the concepts of time evolution, self-organization and multiplicity are introduced in order to discuss the notion of predictive power of a model and to stress that, in complex systems, the space-time scale of self-organization is different from the single sub-systems ones. Finally, the simple model of Schelling about social segregation is illustrated to analyse the relation between a system and its sub-parts in an example concerning the relation between individuals and society and to stress, again, that small (individual) changes can produce big social effects

$5^{\text {th }}$ Political and Economic scenarios: overview of climate treaties and proposals to cut emissions

Lesson 5 provides a framework on political and economic scenarios related to climate change. It moreover illustrates the water and carbon footprints of common habits and daily activity, along with details on energy consumption of households appliances. The aim of lesson 5 is twofold: on a one hand, it aims to make students to understand the role of international climate agreements, and to acquire some knowledge about the current developments towards a global treatise on emission caps. On the other hands, students need to understand that not only policy makers have the power to influence the situation, but also citizens, that with their daily behaviour and habits have the ability to contribute significantly to climate change mitigation.

The core message is that human activity plays a crucial role, both with regard to the collective aspects, related to political and economic scenarios and the institutional choices, and individual aspects related to the behavior of the individual in his daily activities and in its interaction with the environment. 
During the teaching experience many data were collected ${ }^{3}$. In order to answer our research question, we focused the analysis on students' answers to the open-ended questions $\left(\mathrm{Q}_{1}, \mathrm{Q}_{\mathrm{m}}, \mathrm{Q}_{2}\right)$ included in the three questionnaires (Pre-Q, Middle-Q, Post-Q), that were formulated just to follow the development of students' epistemological knowledge about models and modelling. The questions considered are reported in Table 2. We opted for few open-ended questions since we wanted to investigate the evolution of students' thoughts in the structure of their own words (Justi \& Gilbert, 2002; Mendonça \& Justi, 2013).

Table 2. Data Sources and questions on the epistemological dimension

\begin{tabular}{lll}
\hline Data sources & Questions \\
\hline Pre-Q & $Q 1 \quad \begin{array}{l}\text { What is your idea of model in physics? If you think about physical models, what kind of } \\
\text { examples come to mind? }\end{array}$ \\
Middle-Q & $\begin{array}{l}\text { Thinking back to the first questionnaire, how would you answer today? What has } \\
\text { changed in your idea of a model? How has this idea evolved? Make your ideas explicit. } \\
\text { If necessary, you can also give some examples. } \\
\text { In the light of your reviewed ideas and reflections, we ask you to formulate and } \\
\text { describe the model-experiment-reality relationship. } \\
\text { During these lessons, some support concepts have been used as guides. In particular, } \\
\text { great emphasis has been placed on the model - reality-experiment relationship. Could } \\
\text { you describe what you now think about this relationship? }\end{array}$ \\
\hline
\end{tabular}

Students' answers to the questions were analysed through a bottom-up iterative process, aimed at discovering ways to reveal if and how student discourses evolved during the activities.

A global overview of the whole corpus of data showed that two main shifts in students' knowledge occurred: a first shift in their "idea of model" in the step from $\mathrm{Q}_{1}$ to $\mathrm{Q}_{\mathrm{m}}$ and a second shift in the "model-experiment-reality" (M-E-R) relationship in the step from $\mathrm{Q}_{\mathrm{m}}$ to $\mathrm{Q}_{2}$. As we will show, the first shift was still macroscopic. It appears to be the start-up of a process that becomes refined throughout the course and, hence, an ever more subtle feature for observation and interpretation. Given this evidence, the whole picture of the two shifts is relevant in answering the RQ. The second shift was moreover a real challenge from an analytic point of view, requiring the creation of original analytic tools in order to interpret the findings and to allow us to complete the answer to the RQ.

Two kinds of analysis were carried out and compared in order to track if an evolution in students' epistemological reasoning occurred and understand the kind of evolution in the second shift. On one hand, the aim of the first analysis was to explored the nature and the quality of words and lexicon used by the students when they talked about models. In order to do that, we analysed students' answers by using a specific linguistic software (Lebart, Salem, \& Berry, 1998) able to point out emergent threads in students' lexicon. On the other hand, the second analysis aimed to describe how students conceptualize the relationship between model, experiment and reality. In order to do that, we analysed students' answers by coding their statements in terms of patterns of M-E-R relationship.

Operatively, the dual analysis allowed us to identify some operative markers which could reveal if and how students enriched and refined their epistemological knowledge. The markers concern: $i$ ) the use of vocabulary, i.e. the number, quality and semantic fields of epistemological 
words used by the students in writing and talking about modelling physical phenomena; ii) the patterns used by students in talking about the M-E-R relationship. The application of markers to data collected at different points of the classroom activities will allow us to track the evolution of the quality of students' epistemological knowledge.

In order to reach an acceptable level of internal validity, the data were analysed by the authors and by an external scholar (MG), collaboratively and interactively. In such interactions, both the indexing system and the precise classification of all the students' ideas were checked.

In the following section, after presenting the results, their connection with climate change material is discussed. Particularly, we will argue about which specific aspects of the teaching/learning activities on climate change can have contributed to make students' views on models evolve.

\section{Results}

\section{First Shift: Start-up Evolution in Students' Idea of Model}

In the pre-questionnaire (Pre-Q), students appear very confused about the idea of models. In general, only few students ( 6 out of 26) attempted to answer the question and these students borrowed the words from everyday life and commonsense $\mathrm{e}^{4}$. Language and awareness about modelling were not part of their physics background. A synthetic view of the answers is reported in Figure1.

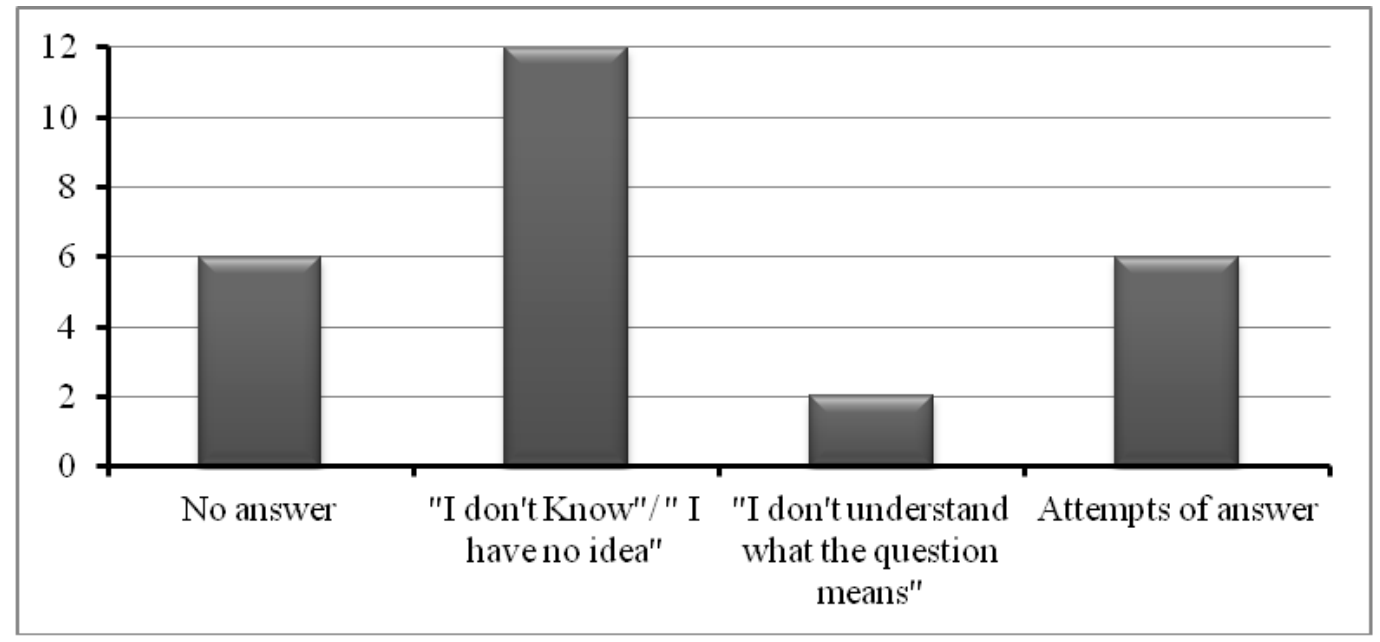

Figure 1. Students' ideas of model in $\mathrm{Q}_{1}$

Most of the students expressed their difficulties in answering the questions through the use of sentences like: "I have no idea what a model is", or "I cannot answer this question because I don't understand what it [the question] means". The 6 students who attempted to answer searched for an example from their common knowledge. Examples included: "A model is, for example, the atomic model" and "For me, a model in physics is a scale model representing something, like in the case of $D N A$ ". Such a result was not surprising since in the Italian physics teaching tradition no special emphasis is given to the models, and a previous pilot-study reported exactly the same reactions (Author, 2013).

After just three lessons, students' answers to the epistemological questions were very different. Their answers to $\mathrm{Q}_{\mathrm{m}}$ were as follows: 
- Nobody answered: "I have no idea".

- All 25 students provided long answers, at least 5-6 lines for each of the three questions;

- Most of them felt the need to stress something like: "Before I had no idea, now I'm reflecting on it and I've clarified something'.

A more detailed phenomenological analysis highlighted two categories of answers, respectively aimed at describing what a model is and what a model is for.

Within the category model is, we identified the following types of answers:

- Model is a description. This includes answers about the descriptive features and role of a model (an example is: "A model is a description of a real phenomenon from a mathematical point of view");

- Model is a simplification. This includes answers in which only the simplification and sterilization of a real-world phenomena is stressed (e.g. "A model is the simplification of a process that we are studying");

- Model is a reproduction. This includes answers which refer to a procedure of copying "something original" or a real-world phenomenon, including scale reproduction or construction of prototypes (e.g. "A model is a microscopic reproduction of what happens in the macroscopic world");

- Model is an experiment. This includes answers in which the basic idea is the complete overlap of meaning between model and experiment (e.g. "A model is an experiment used to test something”);

- Model is a representation. This includes answers in which models are associated to an abstract idea/concept of reality and/or a symbolic exhibition of reality (e.g. "A model is a conceptual representation of something able to explain that something”);

- Model is a construction. This includes answers in which the idea of model concerns not only a mere reproduction of something in reality but also a creation/construction of something abstract that is needed to interpret the reality (e.g. "Model is a construction needed to explain a physical phenomenon");

- Model is a global way of looking at. This includes answers which express a systemic approach and in which models are seen as the lenses needed for looking at the real-world phenomena (e.g. " $A$ model is a global way of looking at a complex phenomenon which is made up of several elements").

Within the category model for, we identified the following types of answers:

- Model is for explaining, e.g. "A model is created for explaining a physical phenomenon";

- Model is for understanding, e.g. "A model, both physical and mathematical, is a gimmick, more or less complex, for designing and understanding natural phenomena";

- Model is for testing, e.g. "Model is a prototype for testing a phenomenon";

- Model is for predicting, e.g. "By means of a model you are able to predict something about the real-world".

Figures 2, 3 and 4 show the distribution of students' answers. 


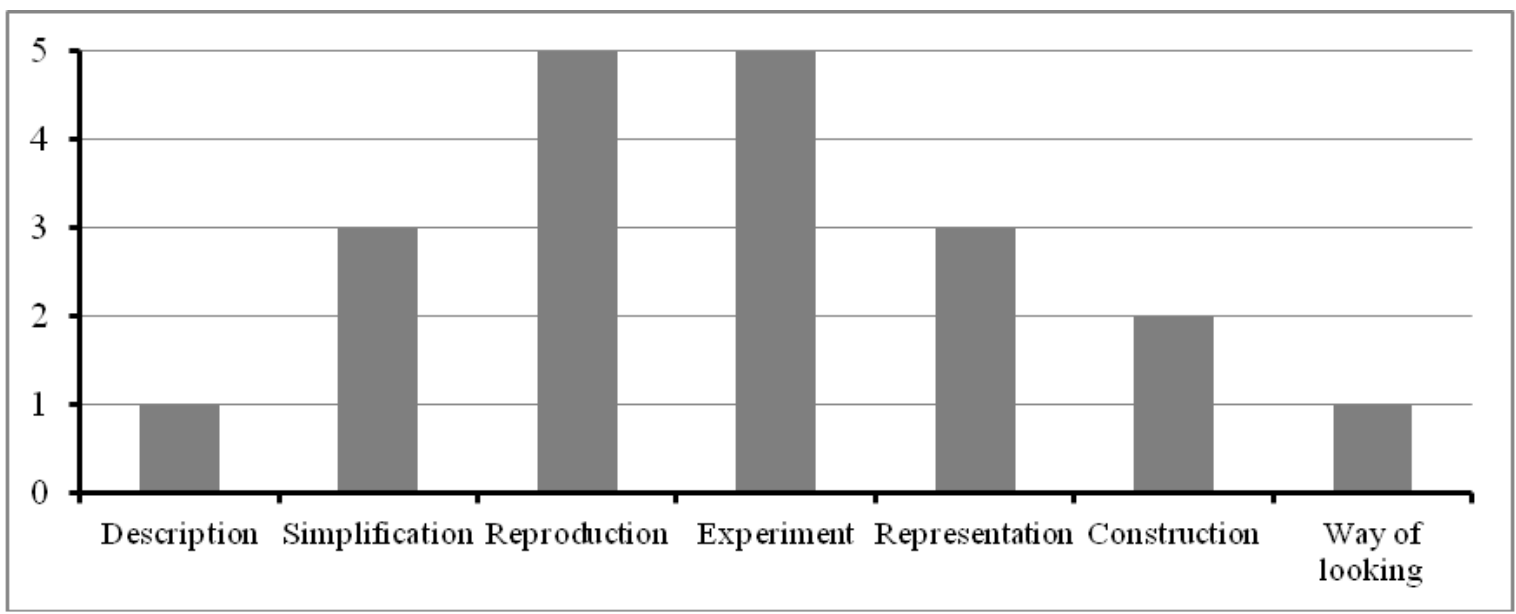

Figure 2. Distribution of students' answers which tackle the definition "Model is"

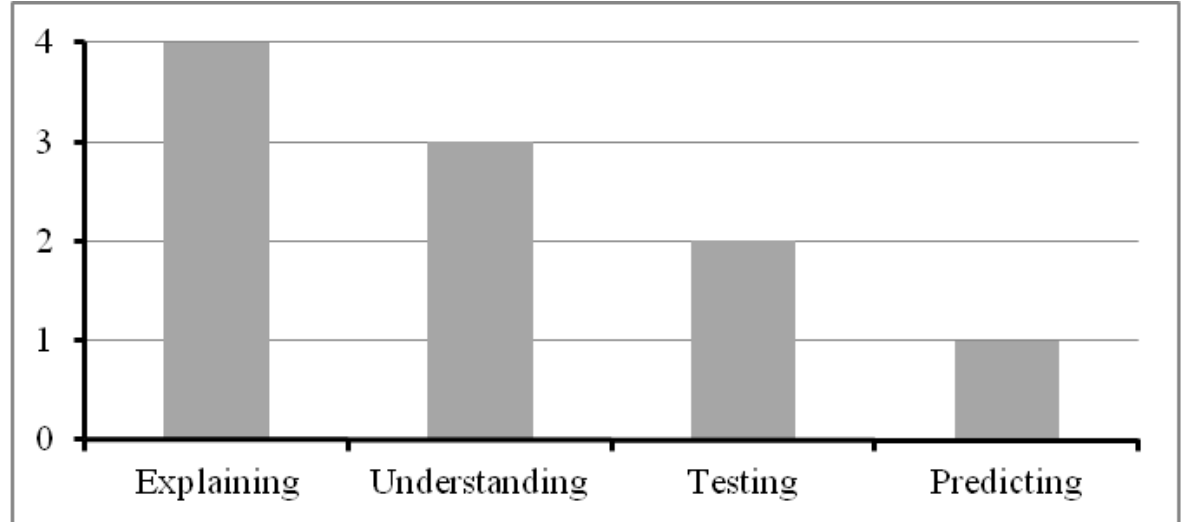

Figure 3. Distribution of students' answers which tackle the definition "Model is for"

\begin{tabular}{|c|c|c|c|c|c|}
\hline & \multicolumn{4}{|c|}{ Model is for } \\
\hline & & Explaining & Understanding & Testing & Predicting \\
\hline \multirow{7}{*}{ 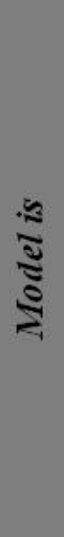 } & Description & & & & \\
\hline & Simplification & & & & $\mathrm{x}$ \\
\hline & Reproduction & & $\mathrm{x}$ & $\mathrm{x}$ & \\
\hline & Experiment & $\mathrm{x}$ & & $\mathrm{x}$ & \\
\hline & Representation & & & & \\
\hline & Construction & $\mathrm{x}$ & $\mathrm{x}$ & & \\
\hline & Way of looking & & & & \\
\hline
\end{tabular}

Figure 4. Distribution of answers which address both "Model is" and "Model is for"

The main conclusions that can be drawn from the data in figure 2 are that: $i$ ) mid-way through the teaching/learning path, the students feel free to express their ideas about what a model is, and the 
answers are distributed over a plurality of ideas; ii) most of the students focus their discourse on model as a reproduction of reality and model as an experiment.

Of the 10 students who provided arguments about the function of models (see Fig. 3). Three of them focused their answers only on what a model is for, without any attempt to provide a definition. The other seven students (see Fig. 4) used the argument model is for to complete and refine their answers. In these cases we see a slight indication that, unlike the case of the pilot-study, the students here were to some extent becoming better prepared to give increasingly refined epistemological views.

\section{Connection between the First Shift and climate change materials}

How can the shift in students' views be interpreted in terms of what students learnt about climate change? Students' views mirror the emphasis paid on experiments during the first part of the labactivities (first three lessons). As briefly reported in table 1, the first set of experiments was carried out to introduce the basic concepts needed to model the process of interaction between radiation and matter (absorbance, transmittance, reflectance, emittance, energy balance, stationary equilibrium). The concepts were progressively discussed and used to interpret the temperature trend of different objects (aluminium and Plexiglas cylinders) exposed to different light sources (Author, 2015). A second set of experiments was carried out with PASCO greenhouse box (ET-8593) aimed to build a simple model for interpreting how changes in the composition of greenhouse gases of the atmosphere produced changes in the average temperature at the Earth surface.

The experiments' implementation was enhanced by collective and peer-to-peer discussions about the relationship between real-world, lab-experiments and theoretical knowledge. The students were guided towards recognizing modelling as a process of isolating a particular phenomenon (greenhouse effect) whose conceptual skeleton has the potential for interpreting also complicated and comprehensive phenomena like global change. By referring to the specific case of greenhouse effect, students were encouraged to recognize that, even though models simplify the reality, they do not represent a scale reproduction. They instead simplify the reality in the sense that they lead to select only those properties that are supposed to grasp the essence of the real-world phenomena. In order to make students to cope explicitly with this issue, they were systematically provoked by questions like: why can we model Earth by an aluminium cylinder, Atmosphere by plastic cylinder, Sun by this bulb? What features of the Earth are we considering when we model it by an aluminium cylinder? Why are they important? What other features are we neglecting? Why this bulb can be consider a reasonable model for the Sun?

Furthermore, in order to enable students to address the well-known difficulties related to construction of the conceptual skeleton of the greenhouse effect (Besson, 2010), students were guided to reflect explicitly on issues like: What kind of properties of the Earth or of the Atmosphere do the models of black bodies of grey bodies express? How can we demonstrate that the property of this cylinder as "being transparent or black" does not depend only on the object but also on the light (radiation)? In what sense can we say that the property of being transparent or black is, at the same time, optical, electromagnetic and thermal?

In the light of the types of activities we carried out in the first three lessons, it is not surprising that, in the intermediate questionnaire, students were able to enrich their views of models and emphasised the role of experiments. It is more surprising the emphasis on the idea of reproduction that is often associated to a scale reproduction. As we argued in the theoretical framework, the ideas 
of models as experiments or scale reproductions are attractive for the students and difficult to problematize. They can represent a point where epistemological discourse becomes stuck and turns into hyper-realistic views. This intermediate result shows limitations in the discourse on models and modelling developed so far. It was not enough to enable students to go beyond the simple idea of models as physical reproduction of objects and phenomena. Further span and a more refined epistemological discourse is needed.

\section{Second Shift: Evolution in Students' Epistemological Reasoning}

During the second part of the teaching/learning experience something more relevant happened. A second, deeper and more refined, shift emerged when comparing students' answers to the same question $\mathrm{Q}_{\mathrm{m}}$ and $\mathrm{Q}_{2}$ about the M-E-R relationship. In order to analyse such a shift, two type of analysis were carried out. They aimed respectively to point out the vocabulary and the patterns that emerged from students' statements about the "M-E-R relationship".

The first evidence gathered from the students' answers emerged from the different vocabulary used in $\mathrm{Q}_{\mathrm{m}}$ and $\mathrm{Q}_{2}$. In order to produce a way to measure the difference, we carried out a guided textual analysis through the use of a linguistic software (Lebart et al., 1998). The aims of the analysis were to understand if there really was a change in the quality of students' vocabulary from $\mathrm{Q}_{\mathrm{m}}$ to $\mathrm{Q}_{2}$ and, in particular, if this change represented an enrichment in students' epistemological discourse. Operationally, the analysis was articulated in various phases. First, the software was applied to students' answers in order to produce an alphabetic list of all the words (substantives, verbs, adjectives, adverbs, articles, etc.) used by the students and to count the frequency of each word. Then, we deleted function words, i.e. those without inherent meaning but functional to the construction of the sentences, like connectors, pronouns, adverbs (e.g. the, if, that). After that, we made a further selection in which we deleted the words whose meaning emerge only at a syntactical level and not at a mere lexical level (e.g. to be, to have, said, factors, etc.).

This operative process gave us a list of words that are meaningful from a lexical point of view, as used by students in their answers, and as a result of their relative frequency. The next phase involved grouping the words according to similarity of meaning and identifying semantic fields, that are presented in table 3 .

Table 3. Description of semantic fields

\footnotetext{
A experimental - including words which refer to typical laboratorial and experimental language like observations, proofs, results

B utilitarian - including words which express an intrinsic finality, in the sense of a utilitarian purpose, like to serve, to use, useful

C reproduction - including words which refer to procedures of copying/duplicating an original thing, including scale reproduction (smaller or bigger than the original). This field includes words like reproduction, scale, reduction

D truth - including words which refer to the quality of being in strict accordance with facts or reality such as truth, real, verified

E similarity - including words which express the distance from reality, referring to something that has the appearance of being real or true and/or shows likeness to real-world phenomena; examples are close to, verisimilar, to mirror
} 


\begin{tabular}{l}
\hline F $\begin{array}{l}\text { simplifying - including words which refer to a simplification or complication of the reality, like } \\
\text { simplify, complex, easy } \\
\text { modelling - including words which mainly refer to the meaning, sense and role of modelling in } \\
\text { understanding physical phenomena, which highlight the presence of ideas, conjectures, hypotheses } \\
\text { in the act of investigating physical phenomena and which are particularly suitable for expressing the } \\
\text { idea of modelling as a creative act; examples include to create, to explain, to interpreter, to } \\
\text { hypothesize } \\
\text { mathematical - including words which refer to the typical language used in maths, like to } \\
\text { demonstrate, calculus, to infer } \\
\text { representation - from the Latin "repraesentare", which means to make it present, to set in view, show, } \\
\text { exhibit, display; this field includes words which portray reality by means of signs or symbols that can } \\
\text { be either concrete entities or abstract; it includes words like represent, representation } \\
\text { context-dependent epistemological words - including words that might carry potentially relevant } \\
\text { epistemological meaning, but whose specific meaning is too context-dependent to be recognised at a } \\
\text { mere lexical level; it includes words like process, mechanism, consequences }\end{array}$ \\
\hline
\end{tabular}

The process of selecting and aggregating the words of both questionnaires into semantic fields was carried out by a team of three researchers who triangulated their analyses (GT, OL and MG). The first two selection phases raised no problems since the criteria for deleting the meaningless words were very simple to apply. Some controversial issues arose, instead, during the processes of grouping the words and identifying the semantic fields. The more controversial issues regarded words that we grouped within the "J category", i.e. words like search, phenomenon, process, mechanism, and consequences, which students could use either within an everyday language domain or within an epistemological discourse. These words were analysed one by one in order to reconstruct their linguistic domain, deleting only those which had no epistemological sense. The graphs below show the results.

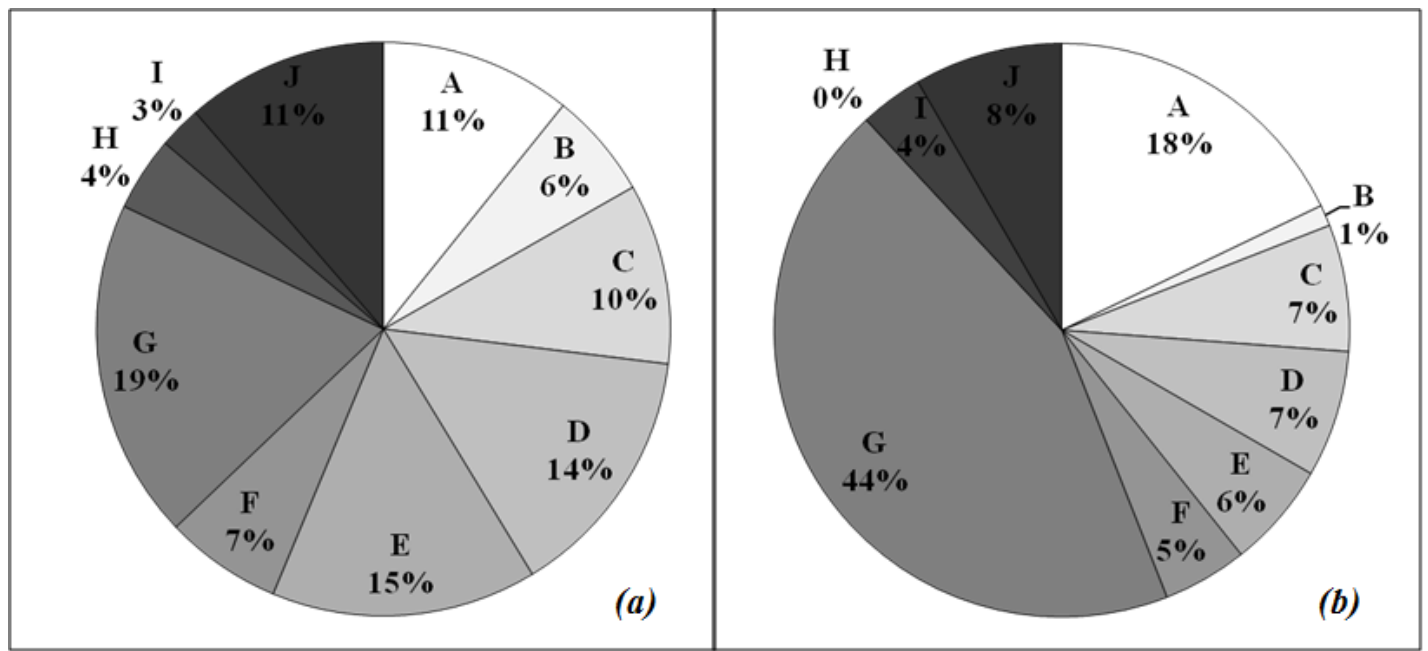

Figure 5. (a) Distribution of semantic fields in Qm; (b) Distribution of semantic fields in Q2

Figure 6 compares the distribution percentages of each field between the two questionnaires. 


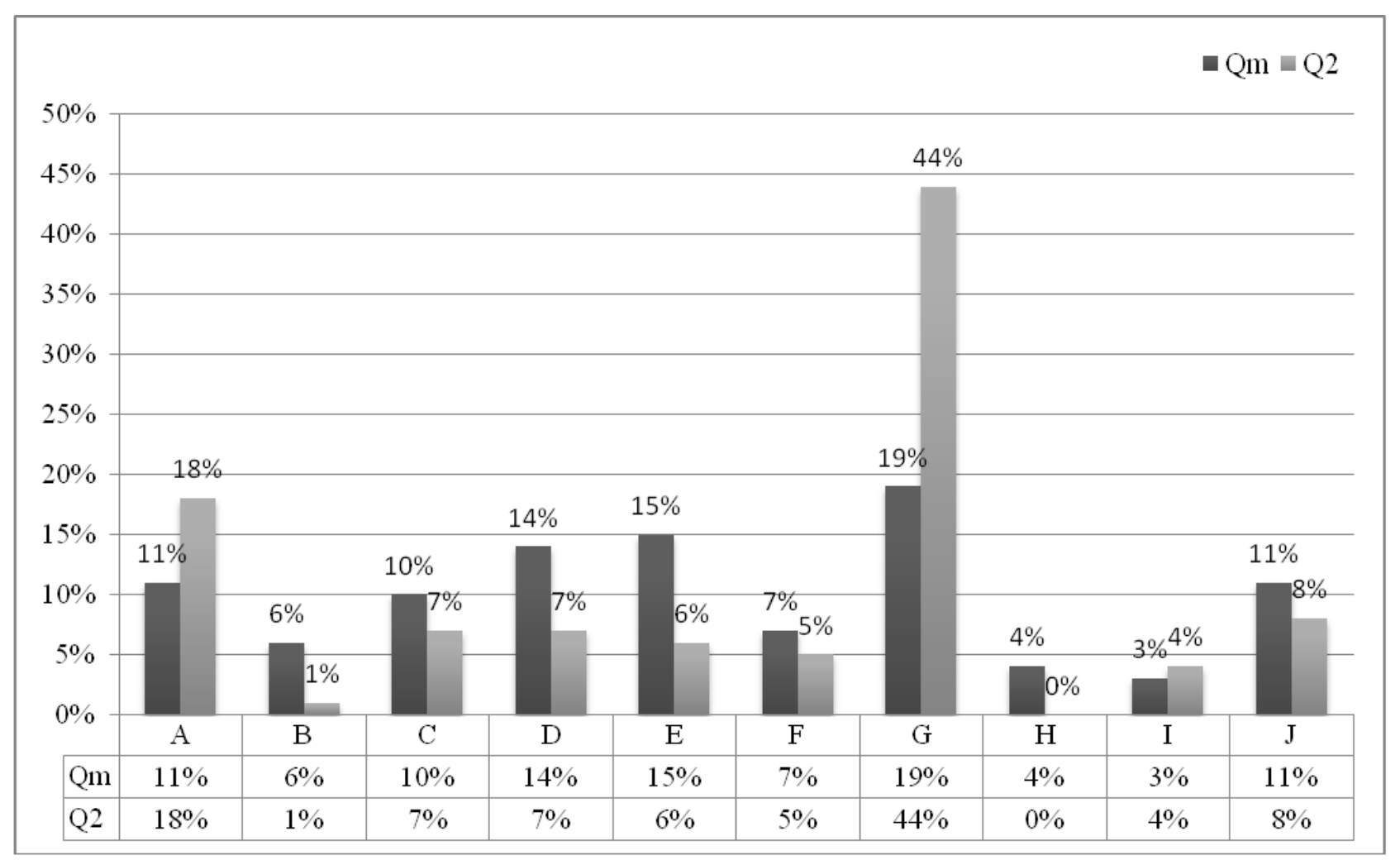

Figure 6. Comparison of semantic fields Qm-Q2

The graphs highlight several changes in the distribution. There is an increase in the experimental field but a decrease in the utilitarian field - this change indicates that the experimental semantic field remains a comfortable register for students but the almost total disappearance of a utilitarian purpose reveals a change in the way they use this language. The almost total disappearance of utilitarian nuances in the language (alongside the increase of the modelling field) demonstrates that the practical and instrumental use of experimental words has given way to a more focused use on the identity and autonomy of the experiment.

The three fields D-E-F registered a substantial decrease, from $36 \%$ to $18 \%$. This result can be interpreted as a signal that the students' language became less oriented to searching for truth or even closeness to reality. In that sense, we see a refinement in students' language that seemed to move progressively away from the naïf hyper-realism reported in the literature. This result is also supported by the decrease of the reproduction field (field $\mathrm{C}$ ) and by the clear increase of the modelling field from $19 \%\left(\mathrm{Q}_{\mathrm{m}}\right)$ to $44 \%\left(\mathrm{Q}_{2}\right)$.

Also, the decrease of the context-dependent field can be read as a sign of improvement: students seem to be able to use a more precise epistemological language. As apparently minor results, the mathematical field $\mathrm{H}$ disappeared in $\mathrm{Q}_{2}$ and there was a relatively modest change in the use of representation words. This initial evidence seems to reflect the fact that, even though mathematical models were widely used and discussed in lessons 2-3-4, the language used by the teachers was in general more physics- than mathematics-related. Verbs like "to show", "to obtain", "to measure", and "to test" were preferred by the teachers to verbs like "to demonstrate", " to deduce", "to calculate" and so on. In contrast, the low recurrence of the word "representation" in student usage appears puzzling, since "to represent" was probably one of the words most frequently used by the teachers. 
This data will be reconsidered in the next analysis since it may constitute a subtle signal that students did not yet feel confident enough with epistemology to use such a demanding word.

As stated in the methods section, the same data were also analysed from another point of view which, as we will see, provided new insights for interpreting the trends observed in the linguistic analysis. In order to carry out this analysis, a selection of students' answers was used to construct a coding scheme for patterns about the M-E-R relationship that we iteratively refined by testing the codes against all the students' answers. This process resulted in the identification of four patterns which express different ways of situating models, experiments and reality in their mutual relationship. The patterns are reported in Figure 7.

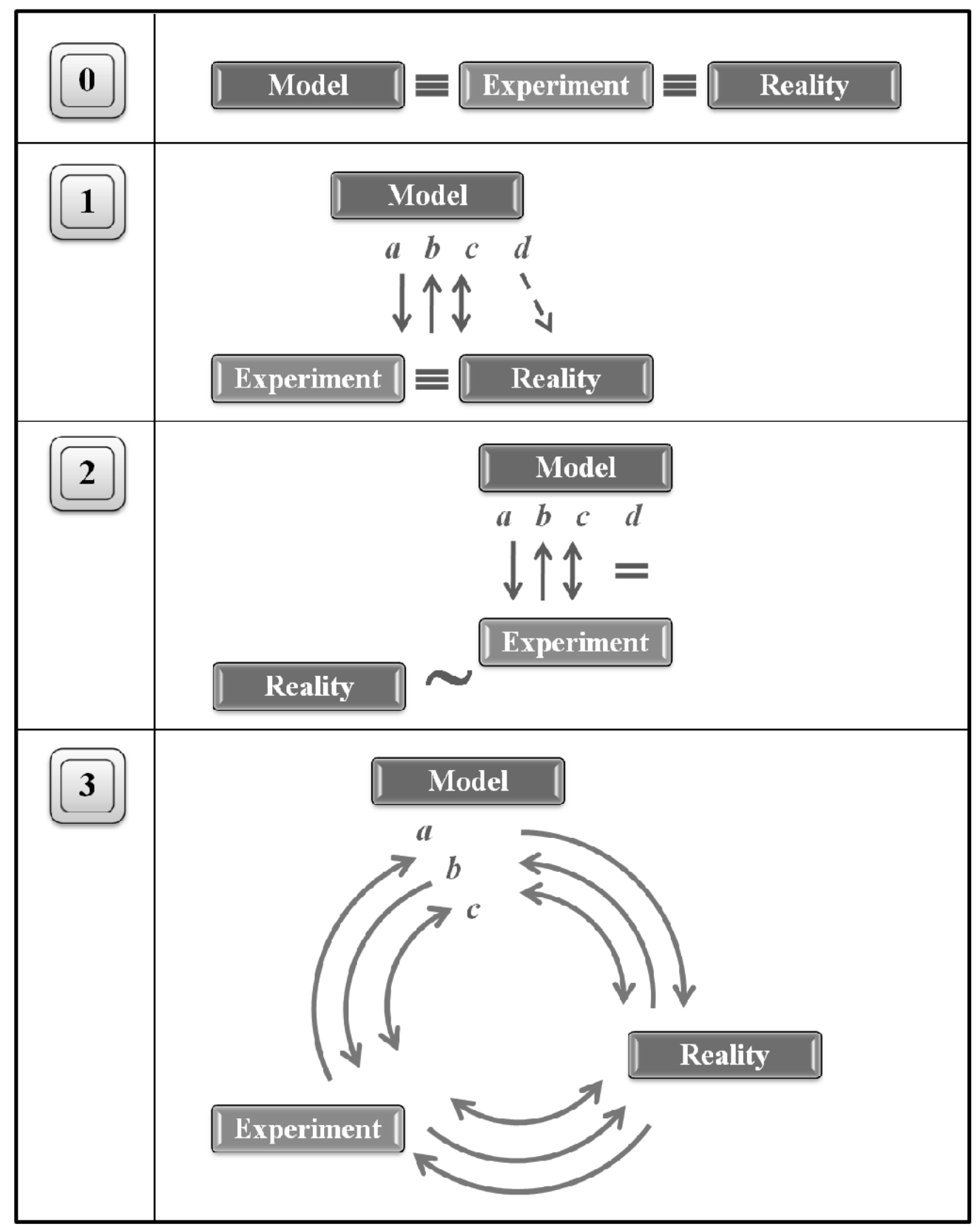

Figure 7. Patterns of M-E-R relationship 
"Pattern 0" represents the identity between Model, Experiment and Reality. Students' answers are ascribed a relationship of identification if they use expressions like "the experiment is/mirrors/reproduces a model".

"Pattern 1" is characterized by the identity between experiment and reality. In this relation a model is viewed as being at another level. A typical answer for this pattern is: "A model is an idea to be tested against experiments/reality". The three different arrows represent three directions of this relationship inside this pattern ("first comes the model, and then its testing"; "model is derived from reality/experiments"; there is no privileged direction). The dashed arrow represents a particular case, here referred to as the "sceptical". This group includes students who do not believe in the effectiveness of the models to understand real world since they perceived them as artificial.

"Pattern 2" is characterized by a relation of verisimilitude between experiment and reality ("experiments consider only some aspects of reality"). Again, the model is posed at another level. The three different arrows represent the previous three directions of this relationship inside this pattern. Moreover, inside this pattern there is a particular relation where students identify model and experiment.

"Pattern 3" is characterized by an iterative relationship among model, experiment and reality. Each term of the relationship is posed on a different level and there is a dynamic (and circular) mechanism among the three. The three different arrows represent three directions of this relationship inside this pattern, specifically, the "a" arrows represents a top-down dynamic (the circular process is initiated by an idea, a model), the " $b$ " represents a bottom-up dynamic (the circular process is initiated by experiments) and the "c" represent a mixed dynamic (sometimes confused). An example of Pattern 3 answers is: "We create a model by looking at the real situation; then according to the obtained results, we conduct experiments".

Figure 8 provides an overall picture of the changes in students' answers and figure 9 shows the shift student by student.

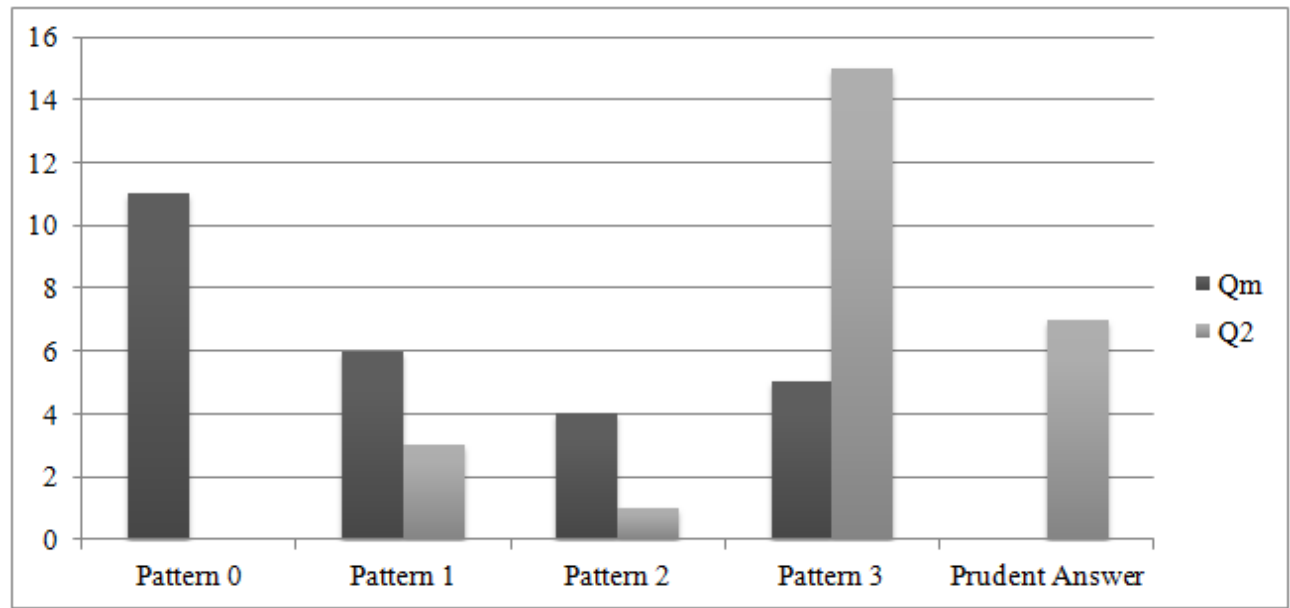

Figure 8. Students' patterns from $\mathrm{Q}_{\mathrm{m}}$ to $\mathrm{Q}_{2}$ 


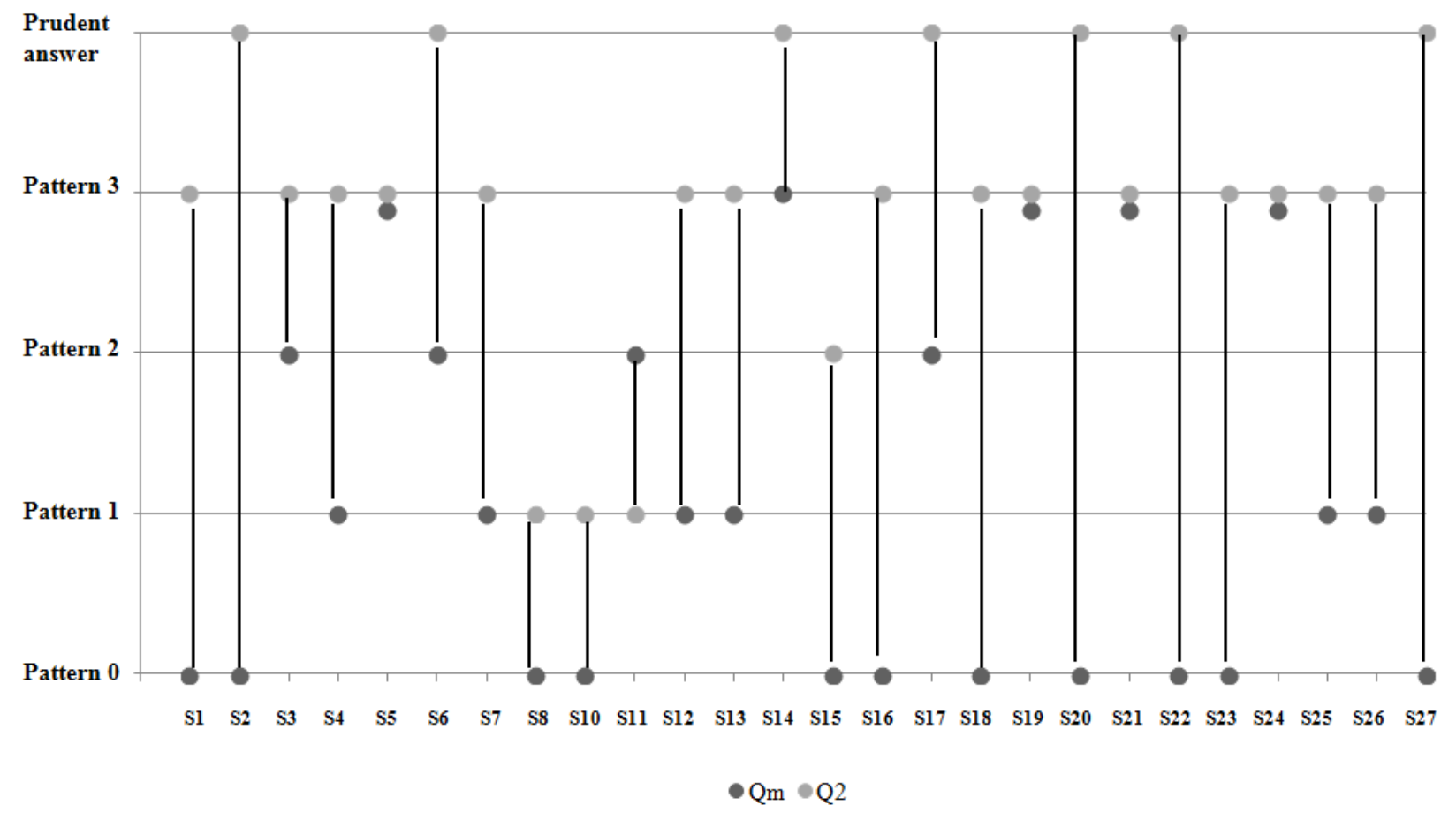

Figure 9. Patterns shift from $\mathrm{Q}_{\mathrm{m}}$ to $\mathrm{Q}_{2}$ student by student

As figure 8 highlights, the most populated pattern in $\mathrm{Q}_{\mathrm{m}}$ completely disappeared in $\mathrm{Q}_{2}$. Where did these students migrate? Figure 9 shows that few students, 3 out of 11, had a small change, i.e., S 8 and S10 shifted to Pattern 1 and S15 shifted to Pattern 2; instead 8 out 11 had a big change, 4 (S1S16-S18-S23) and 4 (S2-S20-S22-S27) migrated respectively toward Pattern 3 and "prudent answers".

The second finding is that "Pattern 3" noticeably increased, from 5 students in $\mathrm{Q}_{\mathrm{m}}$ to 15 in $\mathrm{Q}_{2}$. Which students populated it in $Q_{2}$ ? 4 students (S5-S19-S21-S24) were already in that category, whilst 11 students migrated from low patterns, particularly: 4 from Pattern 0 (S1-S16-S18-S23); 6 from Pattern 1 (S4-S7-S12-S13-S25-S26), 1 from Pattern 2 (S3).

Another substantial findings is that in $\mathrm{Q}_{2}$ a considerable number of students (4 students from Pattern 0, 2 students from Pattern 2 and 1 student from Pattern 3) provided what we called "prudent answer", which is represented by answers like "the relationship is complicated and I still need to think about it". We considered such answers to be evidence that several students are still within a process of epistemological maturation. In this sense, these answers can be related to the other result obtained in the textual analysis (Fig. 6), i.e. the low recurrence of demanding epistemological words like representation. Moreover the students who gave prudent answers expressed a sort of meta-cognitive reflection about the importance on their evolution in grasping the discourses about models.

\section{Connection between the Second Shift and climate change materials}

Students' substantial change in lexicon and in their views about the M-E-R relationship can be easily connected to what they learnt during classroom activities. In particular, we recognise a strong influence of the lesson aimed to introduce the perspective of complexity. During that lesson basic words and concepts typical of the paradigm of complexity were presented: $i$ ) the notion of feedback; ii) time evolution and the probabilistic and projective nature of non-linear models; iii) the 
relation between individual and collective behaviour in the application of the paradigm of complexity to social systems.

The notion of feedback was re-analysed in order to stress the epistemological distinction between linear and circular causality. Linear causality (which is typical of classic mechanistic dynamical models) implies that it is possible to distinguish between cause and effect and that small/large changes in causes lead respectively to small/large effects. On the contrary, by referring to simple math predator-prey models, it was shown that, in circular causality, the distinction between causes and effects becomes fuzzy and small changes can produce large changes or vice versa. The case of melting glaciers was then reconsidered in the light of such a refined causal scheme. As far as the concept of time evolution is concerned, simple examples like Benard cells were considered to discuss how a complex system, such as atmosphere, can over time find new configurations (selforganization) due to a multiplicity of factors, namely: the inner composition of a system, the inner interaction between one sub-systems and another (the fluid molecules), feedback mechanisms, but also, and mainly, collective properties (which cannot be reduced to the sum of the individual behaviours). The introduction of concepts like multiplicity, unpredictability and self-organization was discussed so as to problematize the notion of predictive power of a model and to show that the spacetime scale time of self-organization is different from those of single sub-systems: patterns of collective behaviour can be modelled at an appropriate space-time scale, but they are not predictable according to the behaviour of single sub-systems. Finally, Schelling's simple model about social segregation was discussed so as to re-consider the relation between individual and collective relationship in society and to show how individual choices can produce social changes in a spacetime scale typical of complex systems. This point paved the way toward the final lessons.

The new perspective introduced some fundamental elements that can explain the evolution of students' ideas. These elements are: an explicit discussion about causal knowledge and about dynamical mechanisms of feedback; a critical discussion about models functions and about their effectiveness as predictive tools; an enrichment in the types of models that arrived to include math models and their application to social dynamics. These elements increased the span of types of models and functions, besides introducing new dynamical dimensions for reasoning about models and modelling, namely a new causal scheme and a new view of time evolution. Because of these aspects, it becomes reasonable to think that the second part of the lab-course contributed to break down any static and simplistic overlapping between models and physical reproduction of objects and phenomena.

In other studies on the same data, we demonstrate that the specific epistemological knowledge gained by the students led some of them to feel a new personal and genuine engagement with climate change and to revise their behaviours (Author et al. 2014; Author, 2015a; 2015b; Author et al., under review).

As an example of how students refined their way of reasoning and talking about complex models, like climate, and about modelling in climate change we report a student's sentence: "[in classical physics] I can determine where it will be at a certain point after a certain period of time, whilst here [in the Lorenz's butterfly] I cannot do that. Here it is impossible, I know where such a point moves but I cannot know exactly where it is now. Whereas before the course I was convinced that there was only classic physics, in this case the whole situation has reversed ... and I was a little bit disoriented but fascinated". [Now] I realized that, for example, the melting of glaciers and a rise of just one degree of the average temperature, can lead to important consequences. I understood that these things need to be evaluated on a very dilated scale of time. Whereas I was initially convinced 
that the data variation from year to year was enough to understand these things, changes in the climate, instead I understood that we must have data based on years and years of experience". In this students' words, the connection between models and modelling words and climate science is highly strong. Such kind of students' sentences have been deeply analysed as case study and published in another study (Author, 2015a).

\section{Discussion of the Results}

The analysis showed that the special emphasis placed in the teaching materials on the epistemological discourse of "models and the game of modelling" led the students to acquire and refine their epistemological language. In answering the RQ, we can argue that the overall process of analysis highlighted a two-stage process in the development of students' knowledge: enrichment and refinement.

Enrichment is triggered by the lab-activities (lessons 1-3) and occurred throughout the whole process. During the first three lessons, it resulted in expanding students' ideas about "what a model is" (types) and "what a model is for" (functions). This result leads us to infer that the delicate process of isolating a phenomenon to be investigated in the laboratory, as well as the multiple perspectives (thermal, electromagnetic, optical) from which the GHE was investigated, played a fundamental role in expanding students' reasoning about the meaning and the role of models in science. However, the ideas generated by enrichment are not yet very robust or epistemologically refined: they reveal a strong attention toward the idea of "reproduction" - in terms of scale reproduction and/or phenomenon reproduction through experiments - and toward an "utilitarian" view where there is small room for creativity and thinking. In this sense, after the phase of enrichment triggered by lab activities, students seem still far from problematizing a naïve realist view (Grosslight et al., 1991). Enrichment was moreover enhanced during the second part of the lab-course where both the span in the type and in the function of the models was enlarged. This stage of enrichment represents a threshold value for triggering the stage of refinement.

The stage of refinement corresponded to the two lessons on the epistemological perspective of complexity and the political and economic scenarios of global changes (lessons 4-5). Refinement resulted in a substantial improvement both in students' vocabulary and explanation. In particular, neither experiments are still seen from a simple utilitarian view, nor science is seen as oriented toward a simplistic and rigid view of truth. Whilst, several words used by students to talk about modelling (e.g. to create, investigate, foresee, construct) reveal a change in students' epistemological view where new room is found for creativity, interpretation and invention. This second result leads us to infer that the epistemological reflection on complexity and the application of physical models to social phenomena played a crucial role in helping students problematize the relation between reality, knowledge and experiments by overcoming the known tendency to overlap them in a naïve realistic view. Refinement could occur as soon as the span of the role and the function is large enough to include math and social models.

In order to accomplish our answer to RQ, specific analytic tools have been designed to identify and measure the epistemological refinement that we perceived in students' discourse, as well as to recognize a residual form of lack of confidence in talking about modelling. By means of the first analysis on the lexicon, we were able to track a substantial improvement in the quality and relevancy of epistemological vocabulary used by the students. The low recurrence of the word representation was recognized as evidence of lack of confidence. By means of the second analysis on patterns, we 
were able to track that students overcame their static idea of the relationship between modelexperiment-reality and progressed to recognizing the role of modelling as a bridge between knowledge, real-world and experiment. The presence of what we classified as prudent answers shows that the development of epistemological knowledge is a complicated process, especially if a student arrives from a very different tradition of reasoning. Since the two analytic tools are independent and focused on complementary levels, lexicon and explanation, the comparability and consistency of what they point out provide our results with reliability and confirmability (Denzin \& Lincoln, 2000).

In completing our answer to the RQ, we add two further methodological comments. Firstly, both the tools have been developed in order to relate the results as closely as possible to actual data so as to give the reader not only a picture of what happened in class, but also an idea of the authentic "students' voices". Secondly, the tools function to maximum potential when the aim is to measure a slight change, a refinement, between two close and comparable states of students' knowledge. The same tools would be ineffective if applied to an analysis of the first switch-on shift.

\section{Final Remarks and Implications for Research and for Teaching}

This study originated from the conjecture that climate change represents not only a societal and disciplinary but also an epistemological challenge. Scientific debates imply sophisticated epistemological reflections which refer, more or less implicitly, to a refined way of looking at modelling in climate science. In this sense, the study provided a contribution to a science education research issue that has so far been poorly explored: students' reactions to the epistemological issues raised by the study of climate change.

The research literature on models and modelling widely documents the lack of explicit epistemological stances consciously assumed by the students (e.g., Van Driel \& Verloop, 1999) as well as the strength of views consistent with a naïve realist epistemology. This corresponds to what we found before the development of the teaching path on climate change and we supposed that the roots of such problems could be related to the limited span given to the roles, purposes and functions of models in science (Treagust et al., 2002; Author et al., 2015a). This is what we intended to operate through the development of our multi-dimensional materials and to check with the two-stages analysis.

In the discussion of the results we highlighted that the two stages of students' epistemological development occurred in very precise situations: enrichment was revealed at the completion of the lab-activities (lessons 1-3), and refinement after the two lessons on the epistemological perspective of complexity and the political and economic scenarios of global changes (4-5). Such a correspondence leads us to appreciate that the delicate process of isolating a phenomenon to be investigated in the laboratory, as well as the multiple perspectives from which the GHE has been investigated, played a fundamental role in triggering enrichment and then in expanding students' imagination about the meaning and the role of models in science. Furthermore, the epistemological reflection on complexity and the application of physical models to social phenomena played a crucial role triggering refinement and, then, in helping students to problematize the relation between reality, knowledge and experiments by overcoming the known tendency of mixing and overlapping these issues.

This correspondence leads us to infer that enrichment and refinement are strongly related to the pace of the teaching path and, mainly, to the types and variety of scientific contents developed along it. Our study is another example that shows to what extent understanding is fostered when scientific 
contents are properly illuminated by epistemology and, vice versa, when epistemology is properly grounded on scientific contents, because, freely paraphrasing Lakatos, "contents without epistemology are blind, epistemology without contents is empty"5. Moreover the results of our study appear to point out a threshold stage of enrichment able to trigger the stage of refinement. Threshold appeared when math models applied also to social behaviours were introduced, after a deep reflection about the modelling process occurring in investigative complex phenomena in lab-activities.

These two evidence imply for teaching to take care not only of the span of roles, purposes and functions of models and of the importance of meta-cognitive reflection, but also to pay great attention to that threshold for leading students to go beyond the idea of models as reproduction and to problematize the M-E-R relationship by seeing it as a dynamical and evolutionary relation.

The same evidence imply for research to investigate in more details the relationship between scientific contents and epistemological knowledge, so as to point out when the relationship is cognitively productive and when, on the contrary, introduces useless complications (Author et al., 2013).

One open issue that arises from our specific study concerns the residual lack of confidence that we observed in some students. What is its nature? Can the teaching material be improved and such distrust investigated in more detail?

Another open issue, more relevant for research purposes, concerns the impact of the observed epistemological improvement on other dimensions of learning. In particular, our attention is currently turned towards investigating if and how the improvement of epistemological knowledge affected students' emotional and social attitudes and their personal involvement in CC issue.

In order to address this question, we are carrying out an analysis focused on data collected through the questionnaires and individual semi-structured interviews, which include both societal and epistemological questions.

The results of this analysis are objective of another research work (Author, 2014b; Author, 2015a; 2015b). In particular, we have observed different types of emotional reaction to the epistemological dimension: general acceptance was marked by enthusiastic intellectual satisfaction by some students, with "cold" acceptation, or with prudent and responsible curiosity by other students. What we are finding most stimulating is that the various types of reaction seem to have interesting links with students' emotional and social attitude toward climate change. Particularly interesting for the research are the students who did not care about either physics or climate change issue before the course but who found new personal motives (i.e. intellectual, esthetical, practical) for engagement when they discovered the epistemological perspective of complexity and the new worlds it opened.

\section{Acknowledgements}

The authors thank researchers and teachers who collaborated in the study and offered important suggestions for the analysis, in particular Rolando Rizzi, Paola Fantini, Francesca Pongiglione, Marta Gagliardi, RosaMaria Sperandeo and Claudio Fazio.

The corresponding author especially thanks the Science and Technology Education Group at King's College London, who hosted her, and the European Science Education Research Association (ESERA), who provided financial support for the visit. 


\section{Notes}

1. In the simulations, the relation between the phenomena of absorption and emission is not completely clear, hence several students' difficulties can be related to such an aspect.

2. In the paper, the Authors call "heat" the infrared radiation. We believe that such a choice is deeply dangerous and can be source of serious misunderstanding since it introduces a confusion between two different physical phenomena (transferring energy by heat and by radiation). Such misunderstanding can emphasize well-known problems about heat when students have to study thermodynamics (Besson, 2009).

3. Data tools and students' answers were in Italian, the native language of the students. The whole translations were made or revised from a native English speaker who works in the scientific publishing.

4. Students did not address explicitly models and modelling during their scholastic career. They dealt with models only implicitly during their studies of mechanics, thermodynamics and optics. As far as thermodynamics is concerned, they class had addressed the concepts of temperature, heat, work of dissipative forces and internal energy. During the study of optics they met the concept of light as electromagnetic wave and they had analysed the electromagnetic spectrum.

5. The Lakatos' claim that we are paraphrasing is: "Philosophy of science without history of science is empty; history of science without philosophy of science is blind" (1971).

\section{References}

Barab, S. A., Hay, K. E., Barnett, M., \& Keating, T. (2000). Virtual solar system project: Building understanding through model building. Journal of Research in Science Teaching, 37(7), 719 756.

Besson, U. (2009). Paradoxes of thermal radiation, Eur. J. Phys. 30, 995-1007.

Besson, U., De Ambrosis, A., \& Mascheretti, P. (2010). Studying the physical basis of global warming: thermal effects of the interaction between radiation and matter and greenhouse effect. European Journal of Physics, 31(2), 375-388.

Carey, S., \& Smith, C.L. (1993). On understanding the nature of scientific knowledge. Educational Psychologist, 28(3), 235-251.

Denzin, N. K., \& Lincoln, Y. S. (Eds.) (2000). Handbook of qualitative research (2nd ed.). Thousand Oaks, CA: Sage.

Author (2012). in Fraser, Barry J., Tobin, Kenneth, McRobbie, Campbell J. (Eds.), Second International Handbook of Science Education, Springer Netherlands.

Author et al. (2002). International Journal of Science Education.

diSessa, AA. (2014). The Construction of Causal Schemes: Learning Mechanisms at the Knowledge Level. Cognitive Science, 38(5), 795-850.

Etkina, E., Warren, A., \& Gentile, M. (2005). The Role of Models in Physics Instruction. The Physics Teacher, 44(1), 15-20.

Author et al. (2011). in D. Corrigan et al. (eds.), The Professional Knowledge Base of Science Teaching, Springer Netherlands.

Fazio, C., Battaglia, O.R., \& Di Paola, B. (2013). Investigating the quality of mental models deployed by undergraduate engineering students in creating explanations: The case of thermally activated phenomena. Physical Review Special Topics - Physics Education Research, 9(2), 020101, 121.

Giere, R.N. (2004). How models are used to represent reality. Philosophy of science, 71(5), 742-752. 
Gilbert, J.K. (1995). The role of models and modelling in some narratives of science education learning. Paper presented at the annual meeting of the American Educational Research Association, San Francisco, CA.

Gilbert, J.K. (2004). Models and modelling: routes to more authentic Science education. International Journal of Science and Mathematics Education, 2(2), 115-130.

Gilbert, S.W. (1991). Model building and a definition of science. Journal of Research in Science Teaching, 28(1), 73-79.

Godfrey-Smith, P. (2006). The strategy of model-based science. Biology and Philosophy, 21(5), 725740.

Greca, I.M., \& Moreira, M.A. (2000). Mental models, conceptual models, and modelling. International Journal of Science Education, 22(1), 1-11.

Grosslight, L., Unger, C., Jay, E., \& Smith, C.L. (1991). Understanding models and their use in science: Conceptions of middle and high school students and experts. Journal of Research in Science Teaching, 28(9), 799-822.

Harrison, A.G., \& Treagust, D.F. (2000). Learning about atoms, molecules and chemical bonds: A case study of multiple-model use in grade 11 chemistry. Science Education, 84(3), 352-381.

Hestenes, D. (1992). Modelling games in the Newtonian world. American Journal of Physics, 60(8), $732-748$.

Horizon 2020:

http://eur-lex.europa.eu/LexUriServ/LexUriServ.do?uri=COM:2011:0811:FIN:en:PDF

IPCC (2007). Climate change: Synthesis Report.

Justi, R.S., \& Gilbert, J.K. (2002). Science teachers' knowledge about and attitudes towards the use of models and modelling in learning science. International Journal of Science Education, 24(12), 1273-1292.

Koponen, I.T. (2007). Models and Modelling in Physics Education: A Critical Re-analysis of Philosophical Underpinnings and Suggestions for Revisions. Science \& Education, 16(7-8), 751-773.

Lakatos, I. (1971). History of Science and Its Rational Reconstructions. In PSA (1970), Boston Studies in the Philosophy of Science (vol. 8), edited by Roger C. Buck and Robert S. Cohen, 91108. Dordrecht: D. Reidel.

Lakoff, G., \& Johnson, M. (1980). Metaphors We Live By. Chicago: University of Chicago Press.

Lebart, L., Salem, A., \& Berry, J. (1998). Exploring textual data. Dordrecht. Kluwer Academic Publisher.

Leiserowitz, A. (2006). Climate Change Risk Perception and Policy Preferences: the role of Affect, Imagery, and Values. Climatic Change, 77(1-2), 45-72.

Authors et al. (2013). Science \& Education.

Authors et al. (2014a). Science \& Education.

Authors et al.. (2014b). Procedia - Social and Behavioral Sciences.

Lorenzoni, I., Nicholson-Cole, S., \& Whitmarsh, L. (2007). Barriers perceived to engaging with climate change among the UK public and their policy implications. Global Environmental Change, 17(3-4), 445-459.

Mendonça, P.C., \& Justi, R. (2013). The Relationships Between Modelling and Argumentation from the Perspective of the Model of Modelling Diagram. International Journal of Science Education, 35(14), 2407-2434. 
Millar, R., \& Osborne, J. (Eds.). (1998). Beyond 2000: Science education for the future. London: King's College.

National Research Council. (1996). National science education standards. Washington, DC: National Academy Press.

Nersessian, N. J. (2002). The cognitive basis of model-based reasoning in science. In P. Carruthers, S. Stich \& M. Siegal (Eds.), The cognitive basis of science (pp. 133-153). Cambridge: Cambridge University Press.

Niebert, K., \& Gropengiesser, H. (2012): Understanding and communicating climate change in metaphors. Environmental Education Research, 19(3), 1-21.

Oppenheimer, M., \& Todorow, A. (2006). Global Warming: The Psychology of Long-Term Risk. Climatic Change, 77(1-2), 1-6.

Osborne, J., \& Dillon, J. (eds) (2008). Science Education in Europe: Critical Reflections.

Pasini, A. (2003). I cambiamenti climatici. Meteorologia e clima simulato [Climate Change. Meteorology and simulated clima]. Milano, IT: Bruno Mondadori press.

Pluta, W.J., Chinn, C.A., \& Duncan, R.G. (2011). Learners' Epistemic Criteria for Good Scientific Models. Journal of Research in Science Teaching, 48(5), 486-511.

Pongiglione, F. (2012). The key role of causal explanation in the climate change issue. Theoria $-A n$ International Journal of Philosophy of Science, 27(74), 175-188.

Rocard, M., Csermely, P., Jorde, D., Lenzen, D., Walberg-Henriksson, H., \& Hemmo, V. (2007). Science education now: A renewed pedagogy for the future of Europe. Brussels: European Commission. Directorate-General for Research.

Rozier, S., \& Viennot, L. (1991). Students' reasoning in thermodynamics. International Journal of Science Education, 13(2), 159-170.

Schwarz, C., \& White, B. (2005). Meta-modelling knowledge: Developing students' understanding of scientific modelling. Cognition and Instruction, 23(2), 165-205.

Svihla, V., \& Linn, M.C. (2011). A Design-based Approach to Fostering Understanding of Global Climate Change. International Journal of Science Education, 34(5), 651-676.

Author (2013). Giornale di Fisica.

Author (2014b). E-Book Proceedings of the ESERA Conference 2014, Cyprus 2-7 September 2013. Author (2015a). In Fazio C. \& Sperandeo Mineo R.M., Teaching/Learning Physics: Integrating Research into Practice, Proceedings of the GIREP-MPTL 2014 International Conference.

Author (2015b). PhD-thesis.

Author et al. (under review). International Journal of Science Education.

Authors et al. (2014). Procedia - Social and Behavioral Sciences, 116, 820-825.

Treagust, D., Chittleborough, G., \& Mamiala, T. (2002). Students' understanding of the role of scientific models in learning science. International Journal of Science Education, 24(4), 357368.

Van Driel, J.H., \& Verloop, N. (1999). Teachers' knowledge of models and modelling in science. International Journal of Science Education, 21(11), 1141-1153.

Viennot, L. (2014). Thinking in Physics: The pleasure of reasoning and understanding, Springer Netherlands.

Weintrobe, S. (2012). Engaging with climate change: Psychoanalytic and Interdisciplinary Perspectives. Routledge.

White, B.Y. (1993). ThinkerTools: Causal Models, Conceptual Change, and Science Education. Cognition and Instruction, 10(1), 1-100. 